\title{
Globally Competent Engineers - Do International Experiences Matter?
}

Mr. Alistair Cook, Colorado State University

PhD Student in Education Sciences specializing in global development engineering 


\title{
Globally competent engineers - do international experiences matter?
}

\begin{abstract}
In a world of increasingly complex and trans-national issues, engineers have to become global citizens to manage and understand the multiplicity of complications they face in their professional careers. Engineering design project classes are where engineering students can gain and practice the professional skills they require for their careers and introducing global perspectives is a recognized method to help students understand these skills in other contexts/cultures. Through comparing local and international design projects in classrooms, alongside international experiences through design based study abroad programs and extra-curricular projects we aim to seek to understand the level and role of international experiences in engineering student's global competence. This paper will outline the current research and literature in this area and propose a methodology to compare global competencies of students across four different learning models; a US based, non-development project on campus as part of their curriculum, a contextualized international development project partnering with UNHCR Zambia that the students work on remotely from on campus as part of their curriculum, an extra-curricular design project working internationally on a development project with a partner community and a design project based study abroad project in a developing country. Through this we hope to understand the relative importance of international experience to becoming a globally competent engineer and can students gain a reasonable level of competence through introducing global perspectives into their classroom or do they need to travel abroad?
\end{abstract}




\section{Introduction}

Engineering student's ability to graduate and work in an increasingly global engineering marketplace is fundamental to their future success and careers in this field [2,3]. As part of the changes occurring in engineering education to facilitate this, it is important to understand how different level of international and development experiences in curricular and non-curricular engineering undergraduate design projects effects engineers' preparedness to work globally and in international development. At Colorado State University, a mixed-methods study is being undertaken, to compare and contrast six different curricular and co-curricular model of engineering design teaching, with a mix of international engagement, as shown in the figure below.

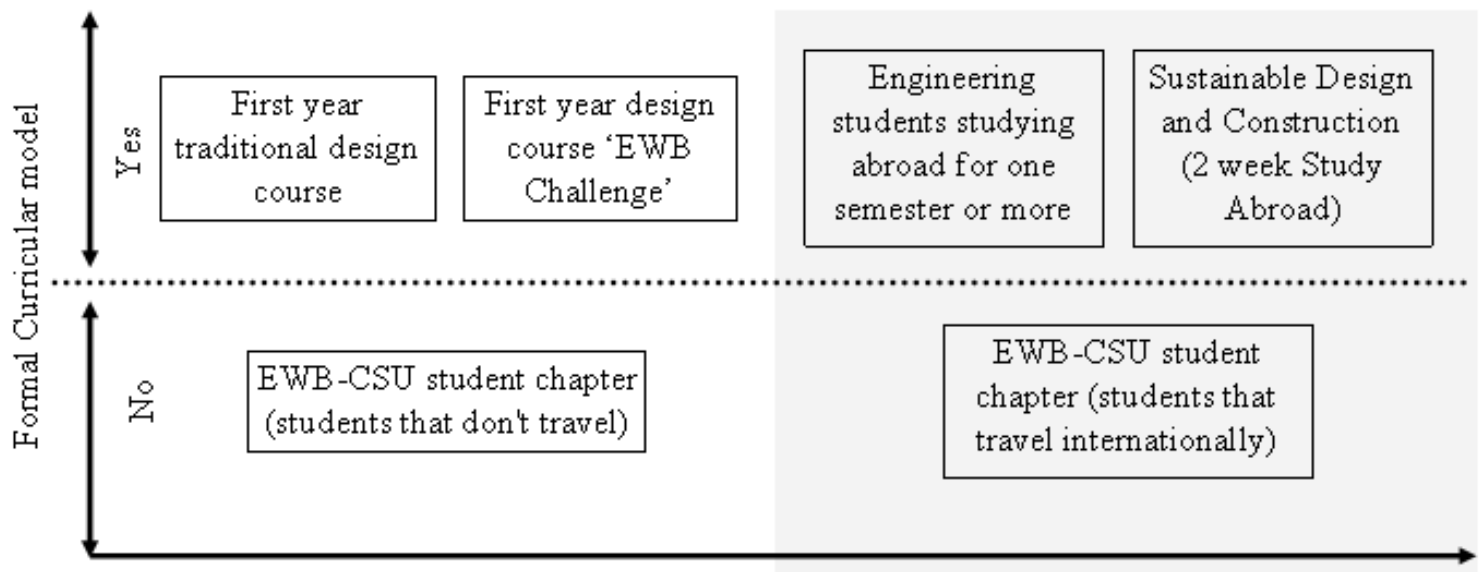

Level of Global Perspectives

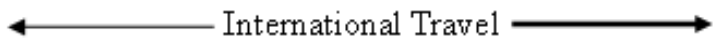

Figure 1- Different Engineering Design Project learning opportunities contained within this study

This matrix, illustrates the difference between the six models being investigated. There are two on campus, curricular design classes being investigated. The first is a first year one semester traditional design course, with a design project component which is based on a water project in Colorado. The second design class is also a first year, one semester design class however the design project in this class is based on the EWB Challenge. This project, developed by EWB-Australia allows students to co-create engineering solutions and management strategies to challenges being faced by the community in the Mayukwayukwa refugee settlement in the Kaoma District of Zambia's Western Province and the local NGO supporting their transition to a permanent settlement, the UN (United Nations) Refugee Agency (Zambia). The EWB Challenge has been piloted at Colorado State University for the past two years [4] and has been successfully undertaken by students across Australia, New Zealand, the United Kingdom and Ireland since 2007 [5, 6]. The other two curricular groups studied are engineering students who will be studying engineering abroad with a partner university for a semester or more, and engineering students undertaking a short term ( 3 week) sustainable design and construction three credit study abroad program in Costa Rica over the winter break. Finally, two co-curricular groups of students will be investigated, members of the universities Engineers Without Borders USA chapter will be looked at as two different groups. Those involved in the design process but that don't travel to the chapters partner community in El Salvador, and those that are involved in the design process on campus and also travel to work with the community. 
Currently, this project is attempting to understand the different instruments available to investigate student's global competency and preparedness to work globally and how to measure and understand the different models used in these six different groups. This paper will expand upon and reflect upon different options for the project.

\section{Global engineering competency}

In engineering, global engineering competency can be seen as inhabiting three dimensions of technical, professional and global domains which contain the skills and attributes of a globally competent, professional engineer [7].

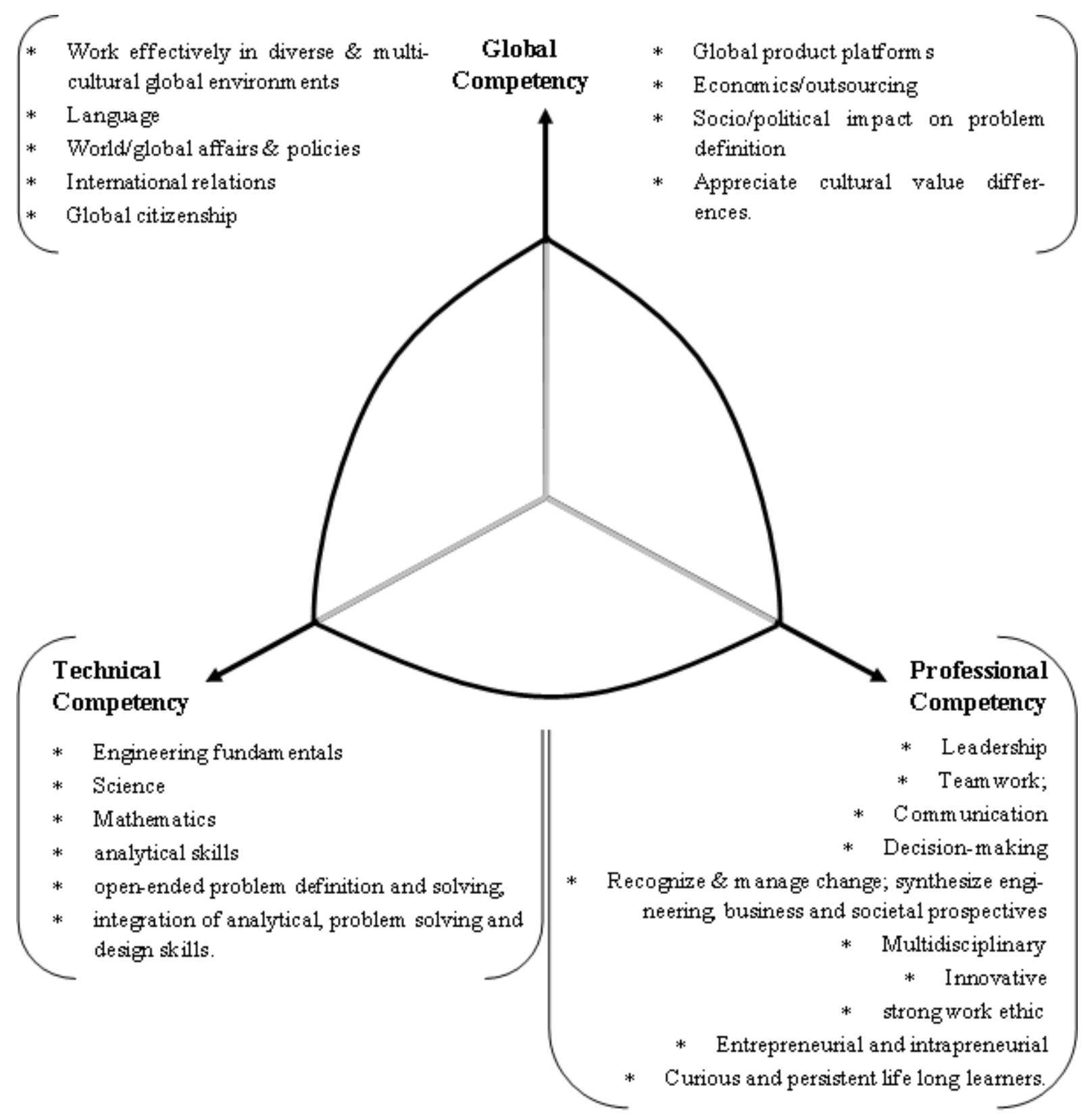

Figure 2 - Attributes of the global engineering professional are conceptualized in a three dimensional space consisting of technical, professional and global domains[7] 
Within this model, the authors suggest that the further along one of the dimension axis the individual engineer is, the closer they are to being competent in that domain. There has been a significant level of knowledge developed around the concept of globally competent engineers such as those presented at the National Summit Meeting on the Globalization of Engineering Education in [8] as part of exploring the rational for teaching globally competent engineers. Brigham-Young University's Mechanical Engineering department worked with their alumni in 48 states and 17 countries to develop a set of global competencies [9]. The American Society of Engineering Education's Special Interest Group on International Engineering Education worked with the International Federation of Engineering Education Societies (IFEES) and the Global Engineering Dean's Council (GEDC) developed and implemented a survey instrument to validate the attributes they saw as essential to a globally competent engineer [10] drawn from this previous work. In the table below, these findings are synthesized to demonstrate some of the similarities and differences found across these studies.

Table 1 - Synthesis of the global attributes of a globally competent engineer

\begin{tabular}{lcccc}
\hline $\begin{array}{l}\text { Skills and attributes (competencies) of the } \\
\text { globally competent engineer [7] }\end{array}$ & $\begin{array}{c}\text { Allert } \\
{[7]}\end{array}$ & $\begin{array}{c}\text { Parkinson } \\
{[8]}\end{array}$ & $\begin{array}{c}\text { Gregg } \\
{[\mathbf{9}]}\end{array}$ & $\begin{array}{c}\text { Huntley } \\
{[\mathbf{1 0}]}\end{array}$ \\
\hline Work effectively in diverse \& multicultural global & $\mathrm{X}$ & $\mathrm{X}$ & $\mathrm{X}$ & $\mathrm{X}$ \\
environments & $\mathrm{X}$ & $\mathrm{X}$ & $\mathrm{X}$ & $\mathrm{X}$ \\
Language & $\mathrm{X}$ & $\mathrm{X}$ & $\mathrm{X}$ & \\
World/global affairs \& policies & $\mathrm{X}$ & $\mathrm{X}$ & $\mathrm{X}$ \\
International relations & $\mathrm{X}$ & $\mathrm{X}$ & $\mathrm{X}$ & $\mathrm{X}$ \\
Global citizenship & $\mathrm{X}$ & $\mathrm{X}$ & & \\
Global product platforms & $\mathrm{X}$ & $\mathrm{X}$ & & $\mathrm{X}$ \\
Economics/outsourcing & $\mathrm{X}$ & $\mathrm{X}$ & & $\mathrm{X}$ \\
Socio/political impact on problem definition & $\mathrm{X}$ & $\mathrm{X}$ & $\mathrm{X}$ & $\mathrm{X}$ \\
Appreciate cultural value differences. & &
\end{tabular}

\section{Assessment and evaluation methods}

Student surveys, student interviews, and focus groups are seen as credible ways of assessing engineering education [11] pertaining to engineering professional skills and global competencies. There are several overlapping areas of assessment and evaluation that can be considered for this topic as methodologies drawn from the following topic areas could be appropriate;

- Students as Global Citizens

- Engineering Students preparedness for working globally

- Evaluation of learning programs

It should be noted that developing assessment and evaluation methods in this area is inherently complex, given the list of areas to be investigated, including ethics, social norms, global difference along with students own biases based on culture, racial and ethnic position, socio-economic status etc. [12] There are also research philosophy and methodological issues to consider, most qualitative measures of global preparedness or awareness are by nature, self-efficacy which may call into question the level of ability of students to self-assess given their respective levels of experience. As an example, a recent study into the EWB-USA chapter at University of Colorado, Boulder found that members of their student chapter 
perceived through self-efficacy surveys based around the ABET criteria to have less technical skills than their peers that haven't been involved in the chapter, but greater broad and holistic skills such as ethics, management, finance and communication [13]. The authors suggest that this is due to the contexts and 'real world' application of skills that the EWB chapter members have experienced, compared with their peers who may not have applied their learning non-academically. This demonstrates the issue of response shift bias within intervention models [14] whereby the intervention causes the participants to re-evaluate the basis of their pre self-evaluation. With a pretest/posttest evaluation model, participants will shift their responses on the post questionnaire based on the new knowledge or levels they have developed through the intervention, without having the opportunity to amend their pre-responses, which often uncovers pretest overestimation [15]. Adding a retrospective pre-test to the posttest allows participants to selfevaluate their change through the intervention, which if a pretest was also performed, can be used to check and shift their initial responses to match the participant's post-intervention levels [16]. There are however some issues with using retrospective pre-tests, namely that it can increase participants desire to show change and they introduce threats to validity such as memory recall, history, and regression towards the mean [17].

\section{Students as Global Citizens}

There are several quantitative measurement instruments developed around the concept of global engineers, one of the most utilized in the US is the Global Perspectives Inventory developed by Global Perspective Institute, Inc. and now hosted by Iowa State University. This inventories purpose is a web based instrument that looks at student's development of a global perspective, incorporating cognitive, intrapersonal, and interpersonal dimensions [18].

Table 2 - GPI Sample Items by Selected Subscales/Constructs [18]

\begin{tabular}{|c|c|}
\hline Subscale/Construct & Sample Index Item \\
\hline Cognitive Knowing & $\begin{array}{l}\text { I take into account different perspectives before drawing conclusions } \\
\text { about the world around me. }\end{array}$ \\
\hline onal Identity & I put my beliefs into action by standing up for my principles. \\
\hline Intrapersonal Affect & I am sensitive to those who are discriminated against \\
\hline $\begin{array}{l}\text { Interpersonal Social } \\
\text { Interaction }\end{array}$ & $\begin{array}{l}\text { I frequently interact with people from a race/ethnic group different } \\
\text { from my own }\end{array}$ \\
\hline
\end{tabular}

\section{Engineering Students Preparedness for working globally}

The Engineering Global Preparedness Index was designed to align the ABET outcomes with the focus of the 'Engineer of 2020' [3], to develop an instrument that would measure how well prepared engineering students are to work in globally focused engineering workplaces [19]. 
Table 3- EGPI Sample Items by Selected Subscales/Constructs [19]

\begin{tabular}{|c|c|}
\hline Subscale/Construct & Sample Index Item \\
\hline $\begin{array}{l}\text { Engineering Ethics } \\
\& \text { Humanitarian Values }\end{array}$ & $\begin{array}{l}\text { Engineers in my country have a moral obligation to share their } \\
\text { engineering knowledge with the less fortunate people of the world. }\end{array}$ \\
\hline $\begin{array}{l}\text { Global Engineering } \\
\text { Efficacy }\end{array}$ & $\begin{array}{l}\text { I believe that my personal decisions and the way that I implement } \\
\text { them in my work activities can affect the welfare of others and what } \\
\text { happens on a global level. }\end{array}$ \\
\hline $\begin{array}{l}\text { Engineering } \\
\text { Global-centrism }\end{array}$ & $\begin{array}{l}\text { I think my country needs to do more to promote the welfare of } \\
\text { different racial and ethnic groups in engineering industries. }\end{array}$ \\
\hline $\begin{array}{l}\text { Engineering Community } \\
\text { Connectedness }\end{array}$ & $\begin{array}{l}\text { To treat everyone fairly, we need to ignore the color of people's skin } \\
\text { in our workplaces }\end{array}$ \\
\hline
\end{tabular}

In a recent collaborative study across three universities in the US, both this and the GPI were utilized along with semi-structured interviews with selected students, framed around the questions;

- Why did you choose to study abroad and/or pursue an international experience?

- Did these experience change the way you think about engineering?

- Did these experiences affect your thinking about the cultural relevance of engineering? [20]

The interview protocol to support these questions was built around the model shown below, also developed by the research team to help them code and analyze the data collected through interview and scaffold their qualitative and quantitative data together.

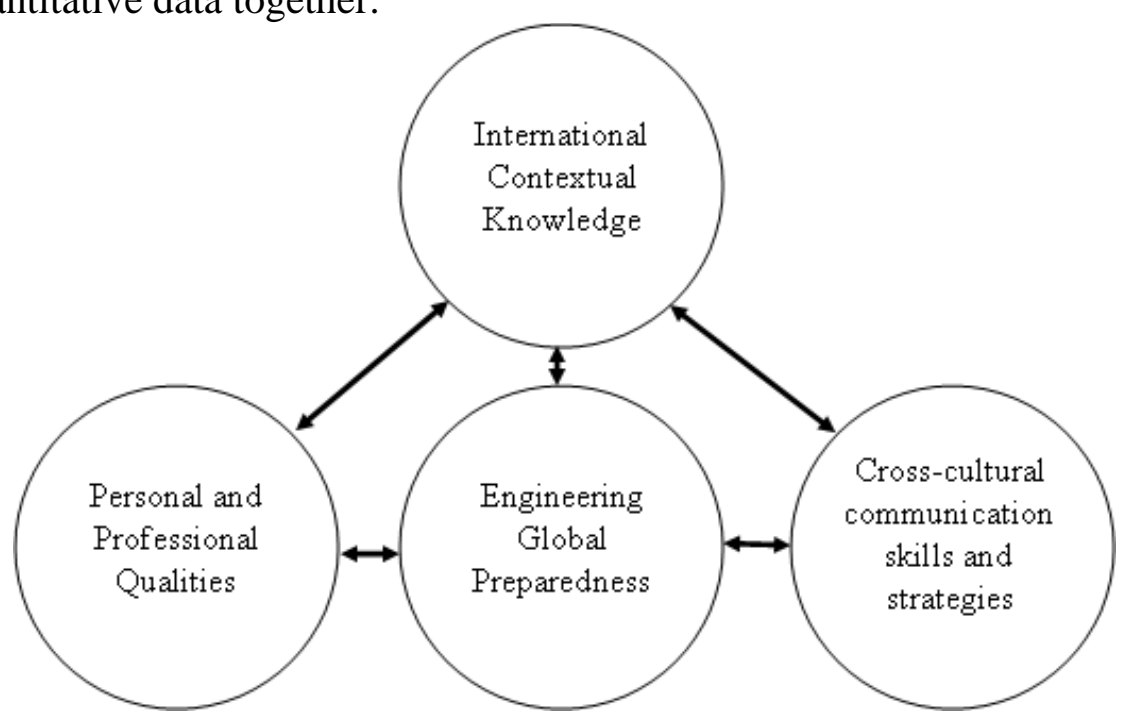

Figure 3 - Simplified Engineering Global Preparedness Semantic Map adapted from [20].

There are also new evaluation methods to measure students' global awareness knowledge, skills, and abilities (KSA) for STEM students, this ongoing research at Pennsylvania State University aims to develop a Model of Domain Learning (MDL) assessment framework for global awareness [21]. The Global Engineering Education Collaboratory (GEEC) based at Purdue University is developing a series of vignettes depicting hypothetical yet realistic global engineering scenarios for use in class discussions as 
part of a situational judgment test (SJT) as a scalable and reliable measure of global engineering competency for engineering undergraduate students as part of an NSF funded research project - Global Engineering Competency: Definitions, Development Paths, and Situational Assessment. [1] Whilst the example vignette that follows is not based in a development context, some global skills and competencies are by nature transferable between different international contexts;

As an employee in a large multinational corporation, you are temporarily assigned to your company's branch operations in Shanghai, China. You are a member of a team consisting of three Chinese engineers, all about the same rank as you. Your team reports to an engineering manager, who is also Chinese. You are in a team meeting where your manager proposes a solution to a difficult quality control problem. However, you are concerned that the proposed solution will fail. Consider these possible actions:

a) Have the entire team approach the manager together.

b) Bring up your concerns in the meeting.

c) Set aside your concerns and follow the manager's lead.

d) Discuss the issue with the manager later, in a private meeting.

e) Consult your Chinese team members about appropriate actions to take.

f) Discuss your concerns with a higher-ranking manager.

Which of these actions (a-f) would you MOST likely take?

Which of these actions (a-f) would you LEAST likely take?

Figure 4 - Example Vignette and Situation Judgement Test [1]

\section{Evaluation of learning programs}

It is also important to be able to evaluate and compare different models of learning in terms of their international factors, both to classify and understand them. The National Summit Meeting on the Globalization of Engineering Education developed a framework of classification factors as shown below [22];

Short-Term versus Long-Term: There are many programs sending students to short-term study experiences and/or visits such as winter- or summer term programs. There are fewer programs involving a fullsemester or academic year.

English Language or Non-English Language: The majority of programs for engineers abroad are conducted in English. Some expect their students to become bilingual and study and/or intern in a language immersion environment.

Degree of Cultural Exposure/Immersion: Many programs are designed to support groups of Americans within their cultural comfort zones, i.e., in English with faculty teaching in accustomed ways. Fewer require the students to adapt to the foreign educational system.

Degree of Curricular Integration: Many programs are built as short-term "add-ons," i.e., summer experiences, and are not integrated into the overall curriculum.

Degree of Cultural/Linguistic Preparation for Experiences Abroad: There is a great range in this regard, with some programs beginning preparation in the Freshmen year and coordinating course selection as a conscious plan anticipating the experience abroad, while others offer little to no preparation. 
Degree of Engineering-Specificity: Some programs are designed to be generalized experiences abroad, without being engineering specific. Others are designed to incorporate engineering education as it is known elsewhere, including professional research, design or internship opportunities.

Degree of Institutional/Administrative Commitment: Some programs are designed and offered by engineering faculty, others are offered by language faculty or study abroad offices, or by external service providers. Some institutions have declared global education for their engineering students to be a high priority. Others see it as a good idea, but not absolutely necessary.

\section{Teaching Practice Inventory}

The Teaching Practice Inventory measures the extent of 'extent of use of research-based teaching practices' or ETP score for each of the eight inventory categories laid out below in the table bellow and by combining these, for the course as a whole. ETP points are given for each practice for which there is research showing that the practice improves learning. How these points are allocated along with references to the research underpinning the scoring rubric is contained with [23]. This instrument has been developed for self-assessment by course instructors to understand how they teach the course.

Table 4 - Teaching practices inventory categories [24]

\section{Inventory Description}

I. Information about the course, such as a list of the topics and organization of the course and learning goals/objectives

II. Materials that support learning of the course content, such as notes, videos, and targeted references or readings

III. What is done in the classroom, including different types of activities that the instructor might do or have the students do

IV. The nature and frequency of homework assignments in the course

V. Testing and grading in the course, as well as the feedback from instructor to students and from students to instructor
Construct

measured

Course information

provided

Supporting

materials provided

In-class features and activities

Assignments

Feedback and testing

VI. Assorted items covering diagnostics, assessment, new methods, Other and student choice and reflection

VII. The selection criteria and training used for course teaching assistants and how their efforts are coordinated with other aspects of the course

VIII. Collaboration with other faculty, use of relevant education research literature, and use of educational materials from other sources
The training and

guidance of teaching assistants

Collaboration

Details on the contents of each construct, including the items which are not scored are outlined below.

Information about the course, such as a list of the topics and organization of the course and learning goals/objectives - this includes all the course information provided to students in hard form or web-based and includes course goals, affective goals, topics, topic related competencies and non-topic related competencies such as critical thinking, problem solving.

Materials that support learning of the course content, such as notes, videos, and targeted references or readings - this includes all supporting materials such as discussion boards, wikis homework solutions, worked examples lecture notes etc. Items that were included but not scored were student wikis or 
discussions with little or no instructor input (those with significant input gain a score) and partial/incomplete PowerPoint slides and lecture notes (again, completed items gained a score.)

What is done in the classroom, including different types of activities that the instructor might do or have the students do - This section scores the different modes of teaching, classes with high amounts of lecturing (over 80\%) score poorly whilst class discussions, student presentations, small group discussions and opportunities for students to ask questions etc. increase the score. Showing demonstrations, video clips etc. were included as was asking students to prepare for class (but not checking they had) but did not gain a score.

The nature and frequency of homework assignments in the course - In this section, graded homework, papers and projects all gained scores, which were doubled if the work was collaborative between students. Ungraded assignments did not gain a score.

Testing and grading in the course, as well as the feedback from instructor to students and from students to instructor - In this section, any feedback collected by instructors from their students, such as mid-term evaluations and paper feedback were included, whilst university mandated post course feedback did not gain a score. All feedback to students, through assignment feedback, individual meetings and exam answer keys gained a score and extra points were given if feedback is provided or an opportunity to redo is given to students before they receive their grade. Extra scores could also be gained if exam questions ask student to explain their reasoning and if the final exam is worth less than $60 \%$ of the total grade.

Assorted items covering diagnostics, assessment, new methods, and student choice and reflection - This section covered pre-assessments to check background knowledge of students, use of pre-post testing by the instructor to measure student learning, consistency in assessment across different offerings of the course to enable comparison, student self-evaluation, student involvement in defining their learning such as being able to choose project topics and new teaching methods or materials that are tried and measured in the course.

The selection criteria and training used for course teaching assistants and how their efforts are coordinated with other aspects of the course - Within this construct, TA training/criteria is measured (note - a score of 3 is given if there is no TA to normalize). Scores could be gained through receiving half a day or more of training in teaching and meeting set English language skills criteria. Most of the available score in this category depended on meetings between the instructor and the TA to discuss the upcoming course material and any student issues.

Collaboration with other faculty, use of relevant education research literature, and use of educational materials from other sources - In this section, levels of collaboration within the department were measured, score could be gained for department provided course materials (rather than using materials provided by colleagues), discussing how to teach the course with colleagues, reading teaching and learning literature relevant to the course and attending colleagues classes to gain or share ideas for teaching. 


\section{Reflection}

There is a fair level of agreement [7-10] on the skills and attributes engineering students need to be globally competent. Understanding and measuring the level of these in classrooms and other learning opportunities is complex, as is measuring all non-technical competencies in engineering. In this study, due to the number of students in each group as shown in the table below it is proposed to utilize two different and overlapping study strategies during the Spring and Fall 2017 semesters to capture the greatest level of breadth and depth possible.

Table 5 - Different learning opportunity models contained within this study

\begin{tabular}{lc}
\hline Learning Opportunity & $\begin{array}{c}\text { Number of } \\
\text { Students }\end{array}$ \\
\hline First year one semester traditional design course & $\mathbf{1 8 0 - 2 0 0}$ \\
First year one semester EWB Challenge design course & $\mathbf{1 8 0 - 2 0 0}$ \\
$\begin{array}{l}\text { Engineering students who will be studying engineering abroad with a partner } \\
\text { university for a semester or more }\end{array}$ & $\mathbf{1 0}$ \\
$\begin{array}{l}\text { Engineering students undertaking a short term (3 week) sustainable design and } \\
\text { construction three credit study abroad program in Costa Rica }\end{array}$ & $\mathbf{\sim 1 5}$ \\
$\begin{array}{l}\text { Engineers Without Borders USA chapter students that travel to the partner } \\
\text { community in El Salvador }\end{array}$ & $\mathbf{\sim 1 0}$ \\
$\begin{array}{l}\text { Engineers Without Borders USA chapter students that partake in the design on } \\
\text { campus but don't travel to the partner community in El Salvador }\end{array}$ & $\mathbf{3 0}$ \\
\hline
\end{tabular}

For all the groups, interviews will be conducted with selected student participants (2-3 from each group) following the protocol laid out by Streiner, McCave [20] utilized in their study of twenty-five engineering undergraduate students at three universities. For these smaller groups, quantitative methods would not be relevant, due to the low number of probable participants. Also for the smaller groups, methods to evaluate different curricular models such as the Teaching Practice Inventory cannot be used, due to the lack of curricular models or support (in the case of the EWB-CSU student chapter groups) and for students studying abroad, each student may be studying in a different university.

However, the two design courses taught at Colorado State University are suitable for a mixed methods studying, supporting the interview data with an appropriate quantitative instrument such as the Global Perspectives Inventory [18] or the Engineering Global Preparedness Index [19]. For these classes, the Teaching Practice Inventory [23] could be utilized with the instructors teaching the course, along with other design project assessments that could be built into the course structure. 


\section{References}

1. Jesiek, B.K., et al., Global Engineering Competencies and Cases, in American Society of Engineering Education International Forum. 2013, American Society of Engineering Education: Atlanta, GA.

2. National Academy of Engineering, Educating the Engineer of 2020: Adapting Engineering Education to the New Century. 2005, Washington, DC: National Academies Press.

3. National Academy of Engineering, The Engineer of 2020: Visions of Engineering in the New Century. 2004, Washington, DC: National Academies Press.

4. Cook, A., T. Siller, and G. Johnson, Creating International Experience for First Year Engineers Through the EWB Australia Challenge Project in ASEE Annual Conference. 2016: New Orleans, Louisiana.

5. Mattiussi, E., The EWB Challenge: Outcomes and Impacts in the UK and Ireland, in Higher Education Academy Annual Conference. 2013, Higher Education Academy: Cardiff.

6. Borrego, M., S. Cutler, and D. Loden. Evaluation of the Engineers Without Borders Challenge at Western Australia Universities. in AaeE Conference. 2010. Sydney: Australasian Association for Engineering Education.

7. Allert, B.I., et al., Making the Case for Global Engineering: Building Foreign Language Collaborations for Designing, Implementing, and Assessing Programs. Online Journal for Global Engineering Education, 2007. 2(2).

8. Parkinson, A., The Rationale for Developing Global Competence. Online Journal for Global Engineering Education, 2009. 4(2).

9. Gregg, M.W., Global Competence: Its Importance For Engineers Working In A Global Environment, in American Society for Engineering Education Annual Conference. 2011, American Society for Engineering Education: Vancouver, BC.

10. Huntley, S., Attributes of a Global Engineer. 2014: American Society for Engineering Education Special Interest Group for International Engineering Education.

11. Olds, B.M., B.M. Moskal, and R.L. Miller, Assessment in Engineering Education: Evolution, Approaches and Future Collaborations. Journal of Engineering Education, 2005. 94(1): p. 13-25.

12. Sperandio, J., M. Grudzinski-Hall, and H. Stewart-Gambino, Developing an Undergraduate Global Citizenship Program: Challenges of Definition and Assessment. International Journal of Teaching and Learning in Higher Education 2010. 22(1): p. 12-22.

13. Litchfield, K., A. Javernick-Will, and D. Knight, Education Without Borders: Exploring the Achievement of ABET Learning Outcomes through Engineers Without Borders-USA, in American Society of Engineering Education International Forum. 2014, American Society of Engineering Education: Indianapolis, IN.

14. Howard, G.S., Response-Shift Bias. Evaluation Review, 1980. 4(1): p. 93-106.

15. Pratt, C., W. McGuigan, and A. Katzev, Measuring Program Outcomes: Using Retrospective Pretest Methodology. American Journal of Evaluation, 2000. 21(3): p. 341.

16. Hill, L.G. and D.L. Betz, Revisiting the Retrospective Pretest. American Journal of Evaluation, 2005. 26(4): p. 501517.

17. Lamb, T., The Retrospective Pretest: An Imperfect but Useful Tool The Evaluation Exchange, 2011. 11(2): p. 18.

18. Engberg, M.E., The Influence of Study Away Experiences on Global Perspective-Taking. Journal of College Student Development, 2013. 54(5): p. 466-480.

19. Levonisova, S.V., et al., Identifying Factors That Enhance Undergraduate Engineering Students' Global Preparedness, in American Society for Engineering Education Annual Conference \& Exposition. 2015, American Society for Engineering Education: Seattle, WA.

20. Streiner, S.C., et al., An Inductive Qualitative Analysis of Student Interviews on Engineering Global Preparedness, in American Society of Engineering Education Annual Conference. 2015, American Society of Engineering Education: Seattle, WA.

21. Chipperfield, S., S. Kulturel-Konak, and A. Konak. Assessing students' global awareness. in Integrated STEM Education Conference (ISEC), 2015 IEEE. 2015.

22. Grandin, J.M. and E.D. Hirleman, Educating Engineers as Global Citizens: A Call for Action / A Report of the National Summit Meeting on the Globalization of Engineering Education. Online Journal for Global Engineering Education, 2009. 4(1).

23. Wieman, C. and S. Gilbert, The Teaching Practices Inventory: A New Tool for Characterizing College and University Teaching in Mathematics and Science. CBE_Life Sciences Education, 2014. 13: p. 552-569.

24. Wieman, C., A Better Way to Evaluate Undergraduate Teaching. Change - The magazine of higher learning, 2015. 47(1): p. 6-15. 